\title{
La imagen de la mujer española en la fotografía de prensa durante la Guerra Civil. Análisis de contenido aplicado a las principales cabeceras portuguesas
}

\author{
Noelia García Castillo \\ Universidad Complutense de Madrid \\ ngcastillo@pdi.ucm.es
}

\begin{abstract}
Resumen:
La Guerra Civil española trajo consigo un cambio en la asignación de roles de género y en la actividad propagandística. El conflicto fue seguido muy de cerca por numerosos países, especialmente por Portugal atendiendo a sus propios intereses. La prensa lusa destinó grandes fondos para cubrir la contienda, pero su seguimiento fue sesgado a favor del bando nacional.

En la presente investigación exponemos los estereotipos y modelos de mujer española presentes en el fotoperiodismo portugués durante la Guerra Civil española, los cuales hemos obtenido tras un riguroso análisis de contenido.
\end{abstract}

Palabras clave: Guerra Civil; Mujer; Estereotipos; Modelos; Fotoperiodismo portugués; Propaganda

\section{The Image of Spanish Women in Press Photography during the Civil War. Content Analysis Applied to the Main Portuguese Newspapers.}

\begin{abstract}
:
The Spanish Civil War entailed an alteration in gender role assignment and propaganda activities. The conflict attracted the attention of numerous countries, especially that of Portugal because of its own interests. The Portuguese Press earmarked considerable funds to cover the warfare, but such coverage was biased in favour of the Nationalist faction.

By means of a thorough content analysis, this paper discusses the stereotypes and models of Spanish women present in Portuguese photojournalism during the Spanish Civil War.
\end{abstract}

Key Words: Spanish Civil War; Woman; Stereotypes; Models; Portuguese Photojournalism; Propaganda.

\section{Referencia normalizada:}

García Castillo, N. (2014): La imagen de la mujer española en la fotografía de prensa durante la Guerra Civil. Análisis de contenido aplicado a las principales cabeceras portuguesas. Historia y Comunicación Social. Vol. 19. Núm. Especial Enero. Págs. 781-795.

Sumario: 1. Introducción 1.2 La mujer en la Guerra Civil 1.2.1. La mujer nacional 1.2.2. La mujer republicana 1.2.3. La imagen de la mujer durante la Guerra Civil española. 2. Metodología. 3. Análisis de los resultados 3.1. Modelos de mujer 3.1.1. La mujer madre 3.1.2. La mujer esposa 3.1.3. La mujer adepta al bando nacional 3.1.4. La mujer falangista 3.1.5. La artista folclórica 3.1.6. La mujer guerrera 3.1.7. La mujer que asiste al soldado. 4. Conclusiones. 5. Referencias bibliográficas. 


\section{Introducción}

La Guerra Civil española supuso un punto de inflexión en la comunicación propagandística. Su repercusión no quedó delimitada a nuestras fronteras. Cabe destacar, dentro de los fascismos europeos, el caso portugués por su cercanía ideológica con el bando sublevado español. Para el Estado Novo era de vital importancia frenar cualquier impulso revolucionario, utilizando para ello los medios que tuviese a su alcance. Uno de sus principales instrumentos fue la censura previa en la prensa (Graça Franco, 1993: 105) mediante la cual se advertía del peligro del advenimiento del comunismo o se mostraba apoyo incondicional a la causa del bando nacional español (Gómez de las Heras, 1992: 273).

Es este contexto histórico uno de los que más periodistas portugueses ha movilizado más allá de sus fronteras, siendo desplazados para la cobertura del conflicto más de una treintena de profesionales entre periodistas y fotógrafos. En palabras de Pena Rodríguez "una victoria franquista significaba un triunfo del salazarismo, un garantía de estabilidad" (1998: 12). Los periódicos incrementaron enormemente sus tiradas desde el estallido del conflicto llegando incluso algunos de estos ejemplares al territorio sublevado español. El trabajo de los informadores portugueses fue el más completo dentro de los medios extranjeros. Sin embargo, este seguimiento fue parcial debido a la ya mencionada censura previa bajo la cual solo tenían cabida las noticias favorables a los nacionales. Así, mediante esta censura se difundían imágenes que hacían "creer al lector que aquello que lee es lo único que existe, que no hay otra versión de la realidad" (Pena Rodríguez, 1998: 114).

\subsection{La mujer en la Guerra Civil}

\subsubsection{La mujer nacional.}

El bando sublevado sostenía que su victoria devolvería a la mujer su posición de "reina del hogar" común al resto de fascismos europeos tras la degradación moral, social y legal que suponía el ideal femenino republicano. A cambio, a la mujer nacional se le requería un "modo de ser alegre y sano" y un "espíritu de servicio y sacrificio" en su maternidad, siendo éste el fin último de la mujer (Gallego Méndez, 1983: $55)$.

La Sección Femenina no toleraba la igualdad de derechos para la mujer. Del mismo modo que resultaba inadecuado su intromisión en asuntos militares o políticos. Con el fin de promover estos principios se procedió a "demonizar" a la mujer republicana o miliciana, asegurando que el mandato divino de jerarquización entre los sexos implicaba una función complementaria de la mujer respecto al hombre.

Las tareas encomendadas a esta mujer definida por unos valores tradicionales fueron diversas. Entre ellas predominaba el rezo, pero también la confección de prendas de abrigo, la cuestación, el cuidado de enfermos, la censura de correspondencia y la atención a los huérfanos. Observamos así que la participación de la mujer es 
esencial, pero en la retaguardia y de manera silenciosa. Salvo situaciones extremas, se desaconsejaba el trabajo fuera del hogar, argumentando la relación del mismo con el descenso de la natalidad e incremento de distintas enfermedades. Sin embargo, lo excepcional del conflicto produjo una serie de llamamientos a favor creando un tipo de mujer que los investigadores dirigidos por Carrionero (1991: 193) han definido como "la esposa, madre o hermana colectiva". En lo relativo a la prostitución, resulta llamativo que mientras la República luchara por su prohibición, la España nacional no procurase acabar con el tráfico sexual.

Algunos autores como Gibaja, Bernalte y Fontecha (1991: 245) describen a la campesina media de la época como un sujeto con tendencia al inmovilismo que acepta su existencia con fatalismo y no reflexiona sobre lo que acontece a su alrededor. El prototipo nacional era fundamentalmente una mujer apolítica que se vio sorprendida por la guerra, sin pretensión alguna de participar como combatiente activa en el frente. A pesar de este imaginario social, Gallego Méndez (1983) apunta que la Sección Femenina requería el desempeño de mujeres con roles activos, contradiciendo así la propaganda que la propia organización se encargaba de difundir.

\subsubsection{La mujer republicana}

La Segunda República y, especialmente, la Guerra Civil española empujaron a cientos de mujeres a una militancia activa insospechada hasta entonces. El caso más dramático es el de la miliciana que, fusil en mano, defendió sus ideales antifascistas. Aun así, muchas de las actividades que éstas desarrollaban tenían más la finalidad de apoyar al soldado mediante "obligaciones femeninas" que de hacer la guerra (Nash, 1999: 165). A pesar de su gran repercusión, estas combatientes fueron una minoría y, tras el verano de 1936, se vieron obligadas a abandonar el frente. De este modo, conforme avanzaban los meses, el esfuerzo propagandístico se centró en situar a la mujer en la retaguardia como una "heroína de la producción", desprestigiando a la mujer miliciana. Una vez abandonado el frente, a las mujeres se les encomendaba levantar barricadas, asistir a los enfermos, confeccionar uniformes y aprovisionar al soldado en las llamadas "campañas de invierno", realizar trabajos auxiliares, alfabetizar e, incluso, trabajar en la industria o el transporte. Además, cabe destacar el apoyo moral que suponía el envío de correspondencia por parte de las madrinas de guerra.

En el segundo año de guerra se recrudece la situación y se insta a las mujeres a evacuar la capital para salvar a la población infantil. Así, cualquiera de las corrientes ideológicas de aquella época coincidía en otorgarle a la mujer el fin último de la maternidad. Carmen Alcalde lo explica apuntando que "las mujeres españolas sólo son madres, sólo son compañeras, sólo son responsables del mantenimiento del hogar, del abastecimiento, de la Cruz Roja, de la enseñanza, de la inyección de calor permanente que necesita el soldado" (1976: 139). 


\subsubsection{La imagen de la mujer durante la Guerra Civil española}

Existe una abundante bibliografía acerca de la imagen femenina presente en la propaganda política. A grandes rasgos, García Alsina (1991: 231) dividió al colectivo femenino durante la Guerra Civil española en, de un lado, las mujeres con conciencia política y, de otro, las mujeres "anónimas", "ignoradas" u "olvidadas", siendo este último el grupo más numeroso.

En aquella época la mujer también fue utilizada como reclamo manipulado con el fin de adecuarse a los distintos ideales. Los principales objetivos de este procedimiento eran elevar la moral entre la población o conseguir simpatizantes para su causa por medio de la pena o la compasión (Julián, 1991: 356).

En lo referido al cartel propagandístico destaca la investigación realizada por Serván Cochero y Trinidad Muñoz (1991). En su estudio concluyen que, pese a la popularidad alcanzada por la miliciana en la prensa europea de izquierdas, el rol predominante en este medio de difusión era la mujer madre y víctima de distintos ataques. La causa de este fenómeno podría apuntarla Mary Nash (1999: 97) con el rechazo que generaba la imagen de la mujer miliciana en el ámbito internacional a la hora de buscar cooperación externa. En el bando nacional, el interés hacia la representación de la mujer se centraba en la función de la misma en el núcleo familiar como medio de reproducción de los valores tradicionales (Gallego, 1983).

De las Heras Herrero (2011) delimitó su estudio al análisis de la representación femenina en los documentos del Fondo Fotográfico de la Guerra Civil Española de la Biblioteca Nacional. La historiadora encontró grandes similitudes entre la mujer madrileña (republicana) y la burgalesa (nacional). De tal modo que en este prototipo conjunto destaca la "mujer tradicional" que de igual modo asiste a los enfermos o interviene en la industria.

Así, como indica Mary Nash (1999: 98), independientemente del bando del que se tratase, no se difundió el modelo de una "nueva mujer" nacida del contexto de cambio, sino más bien uno definido ex profeso para colmar las necesidades político-sociales del conflicto.

\section{Metodología}

El objetivo de la investigación es conocer los estereotipos y modelos de mujer española difundidos por el fotoperiodismo portugués durante la Guerra Civil española. De manera añadida, la hipótesis que pretendemos validar mediante el presente estudio es que dichos estereotipos y modelos son similares a aquellos tradicionales del bando nacional español, mientras que se invisibiliza o demoniza a la mujer republicana. Para el desarrollo del estudio hemos aplicado la metodología del análisis de contenido utilizando la herramienta estadística SPSS. 
Para la selección de las cabeceras hemos seguido las aclaraciones aportadas por Pena Rodríguez (1998), ya que según el investigador el Diário de Lisboa realizó la mejor cobertura del primer año del conflicto con los fotógrafos Deniz Salgado y Afonso Pereira de Carvalho; y Diário de Notícias efectuó la mayor inversión mediante el envío de los reporteros gráficos Teodoro Medel de Aquino, Firmino Marques da Costa y Ferreira da Cunha. Finalmente, decidimos prescindir del análisis de los periódicos O Século y Diário da Manhã por colmar las necesidades informativas con materiales provenientes de agencias de noticias al carecer de fotoperiodistas desplazados al territorio español.

Una vez elegidos para el estudio los periódicos Diário de Notícias y Diário de Lisboa, accedimos a los números publicados entre el 20 de julio de 1936 y el 8 de abril de 1939 con el fin de incluir el análisis del seguimiento portugués de la victoria franquista. Este procedimiento conllevó la extracción de una muestra de 193 fotografías con 437 figuras femeninas españolas.

\section{Análisis de los resultados}

Diário de Notícias es el periódico que incluye más figuras analizadas (62,5\%). El $85 \%$ de las mujeres retratadas aparecen en la portada del diario o bien en secciones especiales para cubrir el conflicto. La práctica totalidad de las fotografías son de autoría anónima, a excepción de nueve casos uniformemente distribuidos entre Firmino Marques da Costa (Diário de Notícias), Campúa (fotoperiodista español independiente de los medios estudiados) y el servicio especial para el Diário de Notícias. El $44,4 \%$ de los personajes aparecían en imágenes cuyas dimensiones se aproximaban a una sexta parte de la página, seguido del $24,9 \%$ que ocupaban un octavo. El plano general es el más abundante $(49,2 \%)$ junto con el plano americano $(27,2 \%)$.

El $52,6 \%$ de la mujeres son fotografiadas en ubicaciones situadas bajo el control del bando nacional, debido a la colaboración ofrecida a los medios portugueses por los sublevados. Esta puntuación se distancia de las mujeres localizadas fuera del territorio español $(19,2 \%)$, en la zona republicana $(14,4 \%)$ o en territorios disputados por los bandos (4,1\%). Cabe destacar el protagonismo de la ciudad de Madrid (13,3\%), así como de Salamanca y de localidades portuguesas (12,1\% en ambos casos).

Es observable un claro predominio de jóvenes (57,9\%), de mujeres que ocupan un primer plano $(68,2 \%)$ y de vestimentas normales o cotidianas $(64,3 \%)$. El 15,6\% portan el uniforme de la Sección Femenina de Falange Española y el 1,6\% el propio del frente de combate, aportando una imagen ideológicamente activa discordante con el ideal femenino del bando nacional, al contrario que la asociada a la vestimenta tradicional o folclórica $(4,1 \%)$. Resulta común la ausencia de cualquier tipo de desnudo $(55,6 \%)$ además de la manga corta $(30,2 \%)$ 
Llama poderosamente la atención que el $50,6 \%$ de las mujeres posen ante las cámaras con una actitud alegre o triunfal, hecho que apunta al fin propagandístico de la comunicación periodística, puesto que el $83,26 \%$ de estas muestras de júbilo tienen lugar en territorios ocupados por los sublevados o fuera de nuestras fronteras. Las muestras de desesperación, tristeza o dolor únicamente alcanzan el 15,6\% de los casos, produciéndose el escaso $23 \%$ de las mismas en localidades controladas por los nacionales.

A pesar de que el 30,9\% de las mujeres no desempeñen ningún rol concreto, esta variable sigue siendo una de las más determinantes en nuestro estudio. Tras dicho porcentaje, los más habituales son aquellos roles catalogados como tradicionales: madres o abuelas $(13,7 \%)$, esposas $(4,3 \%)$ y amas de casa $(3,9 \%)$. A éstos podríamos añadir las enfermeras y cuidadoras o asistentes de soldados (6,7\%), así como a las que se muestran profesando su fe $(3,4 \%)$. Paralelamente, destaca el $28,8 \%$ de mujeres militantes que, desarmadas, manifiestan su apoyo a la causa nacional. El 4,1\% de los personajes son identificados como artistas y el resto de trabajadoras fuera del hogar supone el 2,1\% de la muestra. Por último, aunque sea escasa su aparición, es necesario señalar el 0,9\% de mujeres en actitud guerrera portando armas.

Posteriormente se ha analizado la asignación de roles en las localidades fieles a la República. Al aplicar dicho criterio aumentan las mujeres sin rol específico (39,68\%), las cuidadoras de niños $(20,63 \%)$ y las amas de casa $(17,46 \%)$. Sin embargo, descienden las enfermeras, religiosas y asistentes de soldados, a la vez que no se registra ninguna otra trabajadora fuera del hogar. El $11,11 \%$ de los personajes se muestran como militantes no armadas adeptas al bando nacional. Es decir, en lo que podría definirse como bando republicano, no se difunde la imagen de la miliciana o tan siquiera de mujer favorable a la República. Por el contrario, la imagen que se proyecta es de una mujer incluso más tradicional y apolítica que la correspondiente al bando nacional.

Únicamente el 6,9\% del total de personajes femeninos analizados aparecen en soledad, por lo que en el resto de los casos en que la figura se muestra acompañada se percibe dependencia emocional, tal y como se ha sostenido en numerosas investigaciones acerca de los estereotipos de género en los medios de comunicación. Además, las mujeres acompañadas por una figura infantil alcanzan el $25,4 \%$ de la muestra. Analizando la relación de las figuras con sus acompañantes, el $16 \%$ era de cuidado o protección y el $12,1 \%$ de admiración, aunque el $62,7 \%$ no mostraban vínculo alguno. En lo que respecta al fondo de las imágenes, $68 \%$ de las mujeres son retratadas en espacios abiertos y únicamente el 9,2\% rodeadas de ruinas.

Las palabras clave más frecuentes en los pies de foto son las referencias al miedo o dolor $(12,6 \%)$, el término "refugiado/a" $(10,8 \%)$ y "mujer o joven falangista" $(10,5 \%)$. A esta última debemos añadir "mujer o joven nacionalista" $(3,2 \%)$ para observar una clara intencionalidad de identificar a la mujer con la causa nacional, hecho no observable en el bando contrario. Cabe destacar el 3\% de los casos en los que se comenta la belleza de la mujer y el 5\% de referencias al "humorismo" o a 
"situaciones alegres" observadas en su práctica totalidad en el territorio ocupado por el bando sublevado.

El $65 \%$ de las mujeres son identificadas con el bando nacional mediante algún elemento de su simbología, el pie de foto o por su afinidad con los combatientes. El porcentaje restante corresponde a mujeres que no manifiestan sus preferencias políticas, de modo que la invisibilización de la mujer adepta a la República queda patente. Mediante esta estrategia propagandística resulta innecesario demonizar a la mujer republicana, de modo que el $70,7 \%$ de las figuras reciben valoraciones neutrales en los pies de foto. Una vez desglosado el $14 \%$ de los casos que corresponden a las valoraciones positivas, observamos que el $73,77 \%$ de las mismas se producen dentro del bando nacional y ninguna en la zona republicana o en disputa; el 59\% de las valoraciones positivas las reciben las militantes, por lo que la intención de los diarios era enaltecer este modelo de mujer.

En último lugar, el $8,7 \%$ de las mujeres analizadas soportan una dependencia explícita de un hombre en los pies de foto mediante la mención de sus lazos familiares (esposa, hija, sobrina, etc. de...). Únicamente se aporta la identidad del 14,6\% de las mujeres, en algunas ocasiones con el procedimiento anteriormente expuesto, lo que explica que en la mayoría de ocasiones se traten mujeres que figuran con el rol de esposas o artistas.

\subsection{Modelos de mujer}

Con la finalidad de conocer los modelos de mujer española difundidos por los periódicos Diário de Lisboa y Diário de Notícias durante la Guerra Civil, realizamos un análisis factorial con rotación varimax mediante la herramienta estadística SPSS. La tabla adjunta (Cuadro 1) muestra el resultado de 7 factores determinados por 23 variables dicotómicas que expresaban la ausencia o presencia de ese ítem en cada personaje femenino. El estadístico Kaiser-Meyer-Olkin (KMO) revela la bondad del análisis factorial con un resultado de 0,703. La prueba de esfericidad de Bartlett arrojó un nivel crítico (Sig.) igual a 0.000 por lo que podemos asegurar que el modelo factorial es adecuado para explicar los resultados. Los siete factores mencionados explican el $66,163 \%$ de la varianza. 
Cuadro 1. Resultado del análisis factorial.

\begin{tabular}{|c|c|c|c|c|c|c|c|}
\hline \multirow{2}{*}{ Variables } & \multicolumn{7}{|c|}{ Factores } \\
\hline & 1 & 2 & 3 & 4 & 5 & 6 & 7 \\
\hline Rol de madre o abuela & ,922 & & & & & & \\
\hline $\begin{array}{l}\text { Relación de } \\
\text { cuidado/protección }\end{array}$ & ,813 & & & & & & ,209 \\
\hline Rol tradicional & ,749 & ,430 & & & & & \\
\hline Con compañia infantil & ,692 & & & & & & \\
\hline Rol de esposa & & 854 & & & & & \\
\hline Dependencia & & ,778 & & & & & \\
\hline Relación sentimental & & ,746 & & & & & \\
\hline Mujer identificable & & ,736 & & & ,481 & & \\
\hline Adepta al bando nacional & & & ,787 & & & & \\
\hline En el bando nacional & & & ,754 & & & & \\
\hline Actitud alegre o triunfal & & & ,656 & & & & \\
\hline Referencia al miedo o terror & & &,- 610 & & & & \\
\hline $\begin{array}{l}\text { Uniforme de Sección } \\
\text { Femenina }\end{array}$ & & & & ,853 & & & \\
\hline Rol de militante & & & ,382 & ,663 & & & \\
\hline Falangista o nacional & & & & ,628 & & & 367 \\
\hline Con manga corta & & & & ,609 & & & \\
\hline Mujer joven &,- 331 & &, 310 & 377 & 269 & & \\
\hline Rol de artista & & & & & ,886 & & \\
\hline $\begin{array}{l}\text { Vestimenta tradicional o } \\
\text { folclórica }\end{array}$ & & & & & ,677 & & \\
\hline Valoración positiva & & & & & ,414 & & \\
\hline Mujer armada & & & & & & ,874 & \\
\hline Uniforme del frente & & & & & & ,865 & \\
\hline Rol de ayuda al soldado & & & & & & & ,907 \\
\hline $\begin{array}{l}\text { Porcentaje de la varianza } \\
\text { explicada }\end{array}$ & $20,423 \%$ & $12,145 \%$ & $9,749 \%$ & $7,441 \%$ & $6,240 \%$ & $5,158 \%$ & $4,997 \%$ \\
\hline
\end{tabular}

Fuente: elaboración propia.

\subsubsection{La mujer madre}

El primer factor muestra una mujer que ejerce de cuidadora unos niños a los que ofrece su protección. Recordemos que suponía el 13,7\% de las figuras analizadas. El análisis de contingencia de la variable dicotómica de rol de madre o abuela revela la sobrerrepresentación de este rol en las zonas no controladas por el bando nacional (71,7\% de las mujeres pertenecientes a este modelo). De igual modo se observa su asociación con la actitud de desesperación, tristeza y dolor; la ausencia de identificación con el bando nacional $(61,7 \%)$, y la edad adulta o mediana edad (75\%). En último lugar, resulta llamativo que a pesar de ser el modelo de mujer más defendido por la ideología franquista, en consonancia con los regímenes fascistas europeos, ninguna madre recibe valoraciones positivas en el pie de foto, siendo todas sus descripciones neutrales. 
Imagen 1. Mujer madre.



Fuente: Díario de Lisboa (11-02-37).

\subsubsection{La mujer esposa}

El segundo factor describe esta otra vertiente de la mujer tradicional. Se muestran en una relación de dependencia sentimental respecto a sus maridos. Ellos suelen ser personalidades reconocidas, de modo que el pie de foto permite la identificación de las mujeres por medio del parentesco. Suponen el $4,3 \%$ de la muestra total, pero aparece como un colectivo homogéneo definido por las siguientes características: vestimenta cotidiana o bien elegante/nupcial -atendiendo más al contexto de la fotografía que a la clase social los retratados-, actitud de alegría o gesto neutro y edad adulta o mediana edad $(68,4 \%)$.

Imagen 2. Mujer esposa.

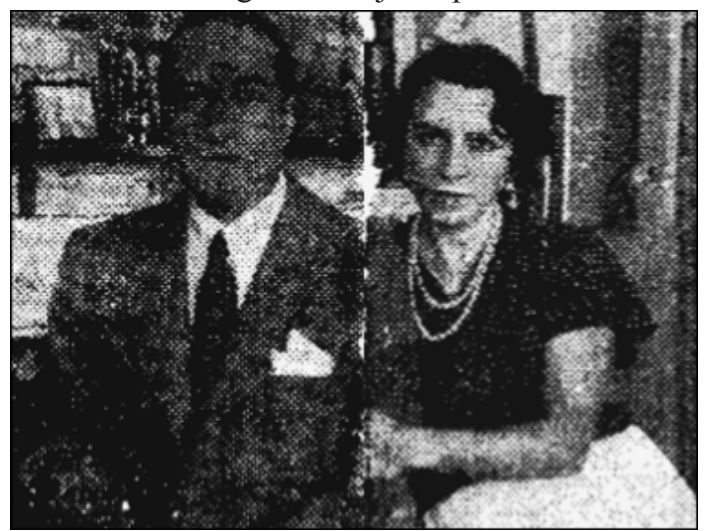

Fuente: Díario de Lisboa (11-07-37). 


\subsubsection{La mujer adepta al bando nacional}

El tercer factor lo compone una mujer situada en zonas controladas por el bando nacional y que comparte abiertamente sus idearios. A diferencia de la "mujer falangista" que expondremos a continuación, no se muestra como miembro activo de ningún movimiento, sino como una ciudadana más que recibe con alegría el triunfo del ejército sublevado. Se trata por lo tanto de un potente elemento propagandístico utilizado para crear una corriente a favor del movimiento franquista como gobierno legitimado por el pueblo una vez liberado de las tropas republicanas. De ahí que no exista conexión alguna de este factor con la aparición en el pie de foto de términos relativos al miedo o terror fruto de la guerra.

Imagen 3. Mujer adepta al bando nacional.



Fuente: Díario de Notícias (02-04-39).

Esta mujer adepta que no porta el uniforme de la Sección Femenina ni ejerce el rol de militante se da en el $14,87 \%$ de los casos estudiados. Suelen ser jóvenes $(69,23 \%)$ con vestimenta normal o cotidiana (83\%), carecen de compañía infantil (83\%) y la relación más frecuente es la de admiración hacia algún sujeto o colectivo $(47,7 \%)$.

\subsubsection{La mujer falangista}

La militante de Sección Femenina se corresponde con el cuarto factor obtenido del análisis estadístico. Ello se observa no solo a través de la indumentaria, sino mediante el uso de palabras clave en los pies de foto. El hecho de que suelan figurar en manga corta parece un dato irrelevante; sin embargo, debemos mencionar que este colectivo era recriminado cuando acudía arremangado a los servicios religiosos. De nuevo se tratan de mujeres jóvenes (86,5\%), en espacios abiertos (90,5\%) y sin relación alguna con el resto de sujetos que las acompañan $(86,5 \%)$, que suelen ser otras mujeres o bien una multitud $(88,1 \%)$. A pesar de ser una mujer contraria al ideal franquista por su activismo político y de no soler acatar la doctrina que se difundía para el resto de 
mujeres, se trata de un modelo de gran calado en la prensa portuguesa del momento. Ello queda demostrado ya que la mujer falangista alcanza el $28,8 \%$ de la muestra total y el $87,5 \%$ de las fotografías del mayor tamaño registrado -media página- incluyen este tipo de mujer que recibe el $59 \%$ de las valoraciones positivas.

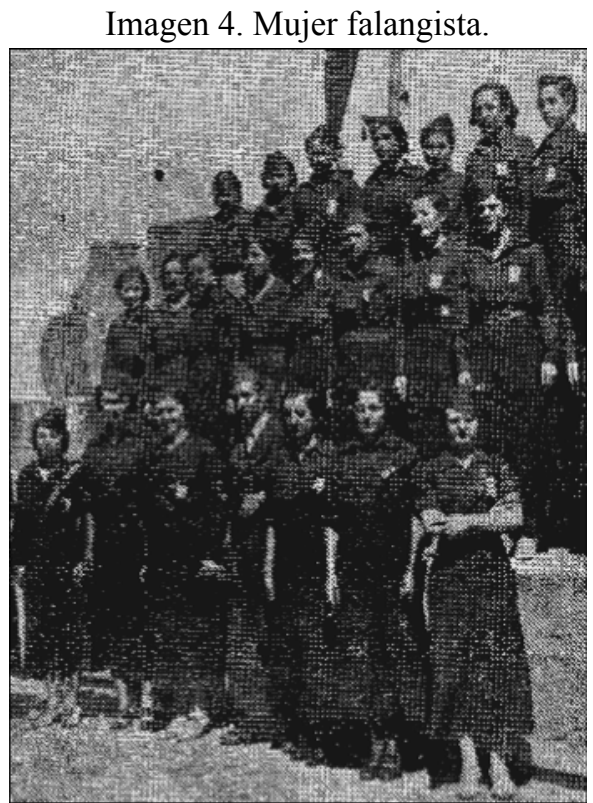

Fuente: Díario de Lisboa (05-08-36).

\subsubsection{La artista folclórica}

El 4,1\% de las mujeres analizadas se corresponden con este quinto factor. El componente "folclórico" parte de los estereotipos acuñados por los viajeros extranjeros del s. XIX a la hora de definir la realidad española. Esta imagen fue explotada por la cinematografía dando lugar al cine costumbrista rural andaluz. Calleja Martín (1991: 124) detalla que, tras el golpe de estado, artistas como Celia Gámez, Estrellita Castro o Conchita Piquer obtuvieron salvoconductos que les permitieron salir a la zona sublevada o al extranjero. Como consecuencia de ello podemos observar en las secciones de cultura y espectáculos de los periódicos anuncios de las actuaciones que algunas artistas españolas representaban en territorio portugués deleitando también a la población española refugiada en el país vecino. El fin comercial de estas comunicaciones explica que el 55,6\% de las artistas reciban valoraciones positivas en los pies de foto. 
Imagen 5. Artista folclórica.



Fuente: Díario de Lisboa (21-12-37).

\subsubsection{La mujer guerrera}

El sexto factor queda recogido en escasos ejemplos $(0,9 \%)$. Todos los casos encontrados pertenecen al primer año del conflicto, periodo que coincide con el de la actividad de la "mujer miliciana". En nuestro caso, hemos descartado el uso de este término por no identificarse esta figura con el bando republicano. Muy al contrario, cabe destacar un pie de página publicado en Diário de Lisboa el 28 de agosto de 1936 que citamos textualmente: "As raparigas nacionalistas seguem o exemplo das milicias marxistas". Todas las "mujeres guerreras" se muestran en esta cabecera sin indicar el bando que controla la localidad en la que se toma la fotografía y sin especificar su adscripción ideológica, salvo el caso anteriormente citado. Al pie de foto reciben en su totalidad valoraciones neutrales, ya que, como hemos dicho, no se han contabilizado casos de valoraciones negativas en la presente investigación. Este análisis podría apuntar a una manipulación propagandística de la "mujer miliciana" por parte de Diário de Lisboa que, sumada su no aparición en Diário de Notícias, suponen la invisibilización de la vertiente de la mujer republicana que más debate académico ha suscitado. 


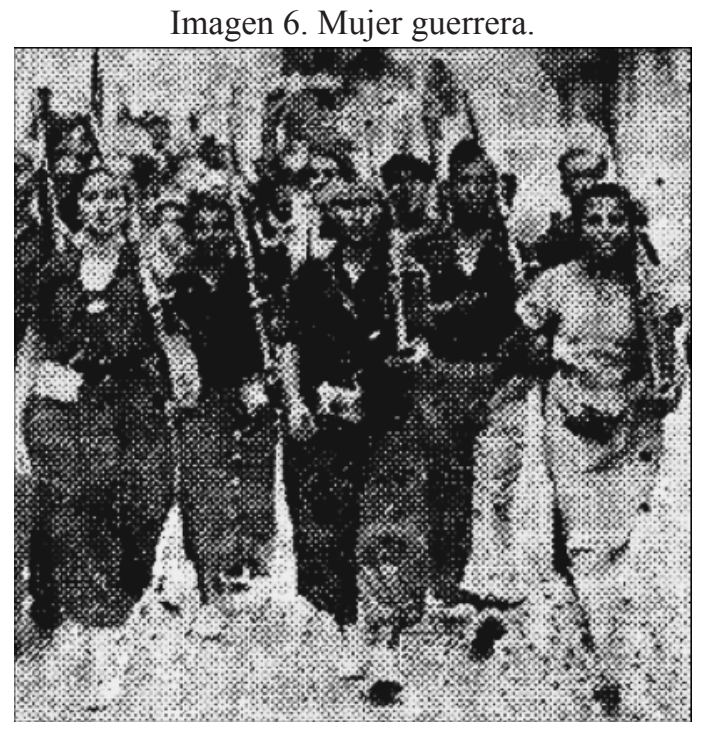

Fuente: Díario de Lisboa (30-08-36).

\subsubsection{La mujer que asiste al soldado}

El último factor queda definido por el 3\% de mujeres que muestran su agradecimiento a los hombres que regresan del frente o bien se unen al esfuerzo bélico adoptando un rol complementario de ayuda al combatiente. Estas figuras femeninas se identifican de alguna manera con el bando nacional, de igual modo que tienden a aparecer en territorios controlados por este bando. Lucen por igual gestos neutros como alegres o triunfales y suelen aparecer con figuras masculinas a las que, en caso de mostrar alguna relación, ofrecen cuidado o incluso admiración.

Imagen 7. Asistente al soldado.

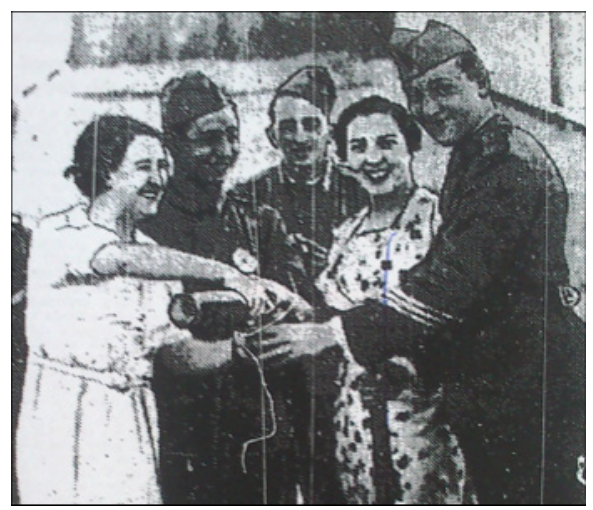

Fuente: Díario de Notícias (11-08-36). 


\section{Conclusiones}

El análisis de contenido aplicado a los 437 personajes femeninos corrobora la gran repercusión mediática que generó en Portugal la Guerra Civil española, así como la significación que los soportes estudiados otorgaron a la imagen de la mujer, concediendo a su vez una mayor validez a nuestra investigación. A través el estudio pormenorizado de las 23 variables hemos obtenido y descrito los estereotipos presentes en las 193 fotografías. Posteriormente, mediante un análisis factorial hemos extraído los siete modelos de mujer que se han relevado como estructuras latentes a partir de esas variables manifiestas: "la mujer madre", "la mujer esposa", "la mujer adepta al bando nacional", " la mujer falangista", "la artista folclórica", "la mujer guerrera" y "la mujer que asiste al soldado".

A la luz de los resultados obtenidos consideramos que queda confirmada la hipótesis de una sobrerrepresentación de la mujer del bando nacional frente a la invisibilización total de la mujer republicana. Tanto Diário de Notícias como Diário de Lisboa retratan con más asiduidad a la mujer popular de la retaguardia republicana, mientras que en la nacional el protagonismo lo ostenta la mujer militante. La mujer nacional juega por lo tanto un rol más activo que el correspondiente al ideal franquista a la vez que este papel recibe mayores valoraciones positivas por parte de los redactores de prensa. Por el contrario, la mujer situada en el bando republicano (ya que carecemos como lectores de indicios de adscripción ideológica a ese bando) coincide en mayor grado con los modelos de mujer-madre y "ángel del hogar".

En último lugar, la visión optimista de la retaguardia franquista recogida en las actitudes de los personajes y en los pies de foto supone una mirada idealizada y no correspondiente con la realidad del conflicto. Este espejismo periodístico que claramente responde a intereses propagandísticos explica también que nuestros resultados no guarden concordancia con los obtenidos en investigaciones anteriores como la realizada por De las Heras Herrero (2011), donde la mujer republicana se mostraba como activa defensora político-sindicalista, mientras que, en el único caso en que la prensa portuguesa indica la ideología de una miliciana, esta mujer es identificada con el bando nacional.

\section{Bibliografía}

ALCALDE, C. (1976). La mujer en la Guerra Civil española. Madrid: Cambio 16. CALLEJA MARTÍN, R. (1991). "Las mujeres de la industria de espectáculos. Madrid (1936-1939)". En Las mujeres y la Guerra Civil española. Madrid: Instituto de la Mujer. p. 118-124.

CORRIONERO, F. et al, (1991). "La mujer tradicionalista: las Margaritas". En Las mujeres y la Guerra Civil española. Madrid: Instituto de la Mujer. p. 188-201.

DE LAS HERAS HERRERO, B. (2011). "Madrid y Burgos, 1936-1939: Representación visual de las mujeres a través del Fondo Fotográfico de la Guerra Civil 
española de la Biblioteca Nacional”. En Discursos fotográficos, nº 10, Londrina: Universidade Estadual, p.147-172.

Diário de Lisboa, 20-07-1936 a 08-04-1939.

Diário de Notícias, 20-07-1936 a 08-04-1939.

FRANCO, G. (1993). A censura à imprensa (1820-1974). Lisboa: Imprensa Nacional - Casa de la Moneda.

GALLEGO MÉNDEZ, M.T. (1983). Mujer, falange y franquismo. Madrid: Taurus.

GIBAJA, J.C; BERNALTE, F.;FONTECHA, A. (1991). "Las mujeres en la retaguardia durante la Guerra Civil". En Las mujeres y la Guerra Civil española. Madrid: Instituto de la Mujer. p. 241-247.

GÓMEZ DE LAS HERAS, S. (1992). "Portugal ante la Guerra Civil Española". En: Espacio, Tiempo y Forma, Serie V, Madrid: Uned. p. 273-291.

JULIÁN, I. (1991). "La representación gráfica de las mujeres (1936-1938)". En Las mujeres y la Guerra Civil española. Madrid: Instituto de la Mujer. p. 353-358.

NASH, M. (1999). Rojas : Las mujeres republicanas en la Guerra Civil. Madrid: Taurus.

PELÁEZ ROPERO, J.M. (1991). "Mujer, poder y represión. La imagen de las mujeres españolas en la cinematografía franquista". En Las mujeres y la Guerra Civil española. Madrid: Instituto de la Mujer. p. 379-383.

PENA RODRÍGUEZ, A. (1998). El gran aliado de Franco : Portugal y la guerra civil española. A Coruña: Edicios do Castro.

SERVÁN, J.; TRINIDAD, A. (1991). "Las mujeres en la cartelística de la Guerra Civil". En Las mujeres y la Guerra Civil española. Madrid: Instituto de la Mujer. p. 364-370.

\section{La autora}

Noelia García Castillo es licenciada en Publicidad y Relaciones Públicas por la Universidad Complutense de Madrid, donde ejerce de investigadora en formación del Ministerio de Educación y Ciencia (FPU). Actualmente trabaja en el Departamento de Comunicación Audiovisual y Publicidad II mientras realiza su tesis doctoral. Sus investigaciones se centran en la representación de la diferencia en los medios de comunicación y en los estudios de género, así como en la historia de la comunicación. 